\title{
EXPERIENCING STREET HARASSMENT AND FEAR OF VICTIMIZATION
}

\author{
Saima Masoom Ali ${ }^{*}$
}

Neelam $\mathrm{Naz}^{* *}$

\begin{abstract}
The debate in acknowledging street harassment as an existing social problem renders research necessary on the topic. Street harassment is said to occur when it takes place in a public setting and is initiated by a stranger. Through this correlation research, we aimed to establish the relationship between experiencing street harassment and fear of victimization. A positive correlation between the experience of street harassment and fear of victimization was hypothesized and a positive correlation between street harassment and negative reaction to harassment was also hypothesized. Additionally, the most recurring type of public harassing behaviors was identified as well. Two self report questionnaires were administered; A gender based harassment scale assessing the frequency of 8 harassing behaviors which ranged on a likert scale from 0 (never) to 4 (almost always) and a modified version of The Fear of Crime survey measuring fear of victimization. These questionnaires were administered to a sample of 250 females recruited via convenient sampling technique that had experienced street harassment previously. Percentages, mode and Pearson's Product correlation were used to statistically analyze data. Results showed a significant, weak positive correlation between street harassment and fear of victimization $(r=.216, p<0.01)$ and a moderate positive correlation between experiencing street harassment and negative reaction towards harassment $(r=.404, p<0.01)$. The most frequent harassing behavior was being stared in a manner that made the victims uncomfortable with $98 \%$ of participants experiencing it, followed by $83.5 \%$ of the participants experiencing non-verbal sounds. Through this research, we were able to conclude street harassment does have negative implications for women.
\end{abstract}

Keywords: Street harassment, women, gender-based public harassment scale

\section{Introduction}

The occurrence of sexual harassment has been rigorously studied in the context of workplace ${ }^{1}$, school ${ }^{2}$ and within relationships, but not much light has been shed on another type of sexual harassment, that is public harassment, also commonly known as street harassment.

\footnotetext{
* Saima Masoom Ali, Ph.D. Assistant Professor, Department of Psychology, University of Karachi

** Neelam Naz, BA (Hon), Department of Psychology, University of Karachi

${ }^{1}$ Louise F. Fitzgerald, Michele Gelfand and Fritz Drasgow, "Measuring sexual harassment: Theoretical and psychometric advances" Journal of Social and Applied Social Psychology, 1995, 425-445.

${ }^{2}$ AAUW Educational Foundation, "Hostile hallways: The AAUW survey on sexual harassment in America's schools" (Washington, DC, 1993).
} 
Research on street harassment has been fairly less owing to the lack of an agreeable definition of street harassment. Nevertheless, street harassment is said to occur when any or all of these conditions arise: passing of verbal or sexual comments, uninitiated, unwanted touching and physical contact, making attempts to coerce a person into complying with sexual demands, ogling (staring in a lecherous way) and stalking; provided these acts occur in a public setting with the perpetrator being a stranger ${ }^{3}$. Research on street harassment has been difficult to conduct because often the incidences of street harassment are so subtle that a large number of women who experience harassment fail to identify or report such behaviors ${ }^{4}$. Faulty beliefs that this type of harassment is less consequential for the victim and the inability to legally prosecute the offenders are few more reasons why research on this topic has not been vast. Furthermore, within certain cultures, street harassment is not considered illegal and those experiencing it may even consider it as flattering ${ }^{5}$. Also, cultural differences in perceiving the act of street harassment need to be understood in order to determine the consequences it has for the victims. Therefore, measuring attitudes regarding street harassment by quantifying the reaction towards such experiences was also one of the goals of this research.

However, lack of research on street harassment does not equate to a lack of occurrence. A study found harassment by a stranger is more widespread compared to harassment from acquaintances and its consequences may create significant and even more harmful results for the victims ${ }^{6}$. In the study, it was determined that stranger harassment makes women feel more fearful of victimization often resulting in restriction of their movements within their environments, looking for alternative routes or avoiding certain areas altogether. The consequences of such behavior would limit women's freedom of movement thus negatively affecting their social as well as economic well being.

Researches in the past few decades verified that women are more fearful of sexual assaults compared to men ${ }^{7}$ and specifically, women confessed to having a higher fear of sexual assault in regard to strangers than acquaintances even though studies claim that they have a higher probability of being sexually assaulted by a non-stranger ${ }^{8}$. Moreover, research is also beginning to address the problem of fear of crime as it's

\footnotetext{
${ }^{3}$ Ross MacMillan, Annette Nierobisz and Sandy Welsh, "Experiencing the streets: Harassment and perceptions of safety among women” Journal of Research in Crime and Delinquency,37, 306-322. (August 2000).

${ }^{4}$ Paula M Meek, "Establishing an informal grievances procedure for cases of sexual harassment of students."Journal of NAWDAC, 1983,46 (2)30-33.

${ }^{5}$ Rhonda Lenton, Michael D Smith et al, "Sexual harassment in public places: Experiences of Canadian women", Canadian Review of Sociology and Anthropology, 1999, 517-540.

${ }^{6}$ Susan E Hickman and Charlene L Muehlenhard, "College women's fears and precautionary behaviors relating to acquaintance rape and stranger rape" Psychology of Women Quarterly (July 2006): 527-547.

${ }^{7}$ Bonnie S Fisher and John J Sloan, "Unraveling the fear of victimization among college women: Is the "shadow of sexual assault hypothesis" supported?" Journal of Justice Quarterly, (August 2006): 633-659.

${ }^{8}$ Shannan M Catalano, “Criminal victimization 2004”. Bureau of Justice Statistics. National Crime Victimization Survey (September 2005).
} 
turning into a social problem with severe negative implications for the individual and society both.

Within the Pakistani culture, the most common forms of street harassment faced by women are unwanted sexual comments, ogling, lewd comments about body and face, brushing against a female's body, pinching and being in a car or bike ${ }^{9}$. Usually, women encounter such behavior when they are unaccompanied by a male companion or when they are with other females. Reporting of street harassment is an additional problem for women because they are made to feel responsible for their own victimization by being told that if a man harasses them, it is because they have been doing something to provoke him ${ }^{10}$.

With an increasing number of women pursuing higher studies and career opportunities, it becomes crucial to ensure their physical and psychological safety in public places. The rationale of this research is to highlight the occurrence of street harassment as a prevailing social problem. Therefore, this research was conducted to examine the extent to which experiencing street harassment and fear of victimization are correlated. The hypothesis suggested there will be a positive correlation between the experience of street harassment and fear of victimization of those affected by it. Another hypothesis also stated that a positive correlation between experiencing street harassment and negative reactions towards harassment will occur. Moreover, this research will also throw some light on the most commonly occurring harassing behaviors.

\section{Methodology}

\section{Sample}

The sample consisted of 250 women aged 18-35 residing in Karachi and they were recruited through convenient sampling technique after ensuring the participants fit the inclusion criterion which was to been through at least one experience of street harassment within the past two years.

\section{Instruments}

Gender-Based Public Harassment Scale ${ }^{11}$

Most scales on sexual harassment either measure harassment at workplace (SEQ) or partner harassment, therefore a relatively new scale 'Gender-based Public Harassment' Scale was used to measure participants' responses to street harassment. This self report questionnaire is divided into two subscales: (1) Harassing Experiences $(a=.807)$ which measures eight types of harassing behaviors and the frequency with

\footnotetext{
${ }^{9}$ Anila, "Perception of sexual harassment among a group of male and female medical college students", Pakistan Journal of Psychological Research, (1990),55-67.

${ }^{10}$ Anila, "Sexual harassment: Myths versus women's reality". Paper presented at the $8^{\text {th }}$ International Conference of Pakistan Psychological Association, Islamabad, (1991).

${ }^{11}$ Lord, T. L. "The Relationship of Gender-Based Public Harassment to Body Image,Self-Esteem, and Avoidance Behavior". Indiana University of Pennsylvania, (2009).
} 
which the participants experience each behavior. The score for each item ranges from 0 (never experience it) to 4 (almost always experience it) and (2) Reaction to Harassment $(\mathrm{a}=.795)$ which consists of a semantic differential scale including 5 items which assess the reaction of women regarding their experience with street harassment. Scores of Reaction to Harassment scale range from 1 to 7.

Fear of Crime Survey ${ }^{12}$

A modified version of the Fear of Crime in America Survey was administered to the participants in order to measure their fear of victimization. The survey consisted of 15 statements depicting scenarios of various kinds of crimes that ranged from "Fear of being cheated, conned, or swindled out of money" to "Fear of being sexually assaulted or raped". The participants rated their fear of each crime on a scale from 1(not at all afraid of this incident) to 10 (very afraid of this incident).

\section{Procedure}

Participants were recruited through a convenient sampling basis after ensuring the inclusion criteria was met - they should have had prior experience with street harassment within the past two years. Because of the sensitive nature of the concerned issue, potential participants were contacted online (through e-mail addresses and social media such as twitter, facebook etc) and informed regarding the purpose of the study. They were asked to fill out an informed consent which included the key question regarding their past experience with street harassment operationally defined as being subjected to any of the following events in a public setting by a stranger within the past two years: being targeted with sexual/verbal comments; unsought and unwanted touching and physical contact; attempts to compel a person into fulfilling their sexual demands; staring in a lecherous manner and stalking; the consent form also mentioned that participation was voluntary; all the personal information was confidential and the participant could withdraw at any point they wished to do so. After agreeing with the terms, the participants had to fill out a demographic form and then complete the Gender-based Public Harassment (Appendix A) and Fear of crime (Appendix B) questionnaires. The contact information of the researcher was provided if the participants required further debriefing.

\footnotetext{
${ }^{12}$ Ferraro, K. F., \& LaGrange, R.L. Are older people most afraid of crime? Reconsidering age differences of
} victimization. Journals of Gerontology, (1992) 47, S233-S244. 


\section{Results}

Descriptive statistics have been illustrated in table 1- percentages of participants experiencing each behavior on the Harassing Experiences Subscale.

\begin{tabular}{|c|c|}
\hline Items & $\begin{array}{l}\% \text { of participants experiencing the } \\
\text { harassing behavior }\end{array}$ \\
\hline $\begin{array}{c}\text { Stared in a manner that made them feel } \\
\text { uncomfortable }\end{array}$ & 98 \\
\hline Non verbal sounds (whistling, hooting) & 83.5 \\
\hline Gestures that made them uncomfortable & 65 \\
\hline Indecent exposure by men & 47 \\
\hline $\begin{array}{c}\text { Receiving comments on physical } \\
\text { appearance }\end{array}$ & 74.5 \\
\hline Vulgar, derogatory or insulting comments & 38 \\
\hline Being followed by a stranger & 72 \\
\hline Unwanted touching by an unknown person & 69 \\
\hline
\end{tabular}

This table shows out of 250 participants, in percentages, how many of the participants experienced each harassing behavior.

Table 2 demonstrates descriptive statistics- mean and standard deviation of the harassing behaviors experienced by participants where the response options were between $(0=$ never, $1=$ rarely, $2=$ sometimes, $3=$ often and $4=$ almost always. $)$

\begin{tabular}{|c|c|c|}
\hline Item & Mean & Standard Deviation \\
\hline $\begin{array}{c}\text { Stared in a manner that made them feel } \\
\text { uncomfortable }\end{array}$ & 2.63 & 1.07 \\
\hline Non-verbal sounds (eg: whistling, hooting) & 1.46 & 1.03 \\
\hline Gestures that made them uncomfortable & 1.05 & 1.02 \\
\hline Indecent exposure by men & 0.67 & 0.86 \\
\hline Receiving comments on physical appearance & 1.67 & 1.18 \\
\hline Offensive, derogatory or insulting remarks & 0.63 & 0.91 \\
\hline Being followed by a stranger & 1.14 & 0.97 \\
\hline Unwanted touching by an unknown person & 1.12 & 1.02 \\
\hline
\end{tabular}

Table 2 shows how often each of the harassing behaviors on the Harassing Experiences Subscale was experienced by the participants. 
Table 3 depicts the most popular response and the \% of participants that chose that response in the Reaction to Harassment Subscale. Please refer to Appendix A to view the complete list of options for this Sub Scale.

\begin{tabular}{|c|c|c|}
\hline Items & Most answered & $\begin{array}{c}\text { \% of participants who chose this } \\
\text { answer }\end{array}$ \\
\hline Worried-Calm & Very worried & 67.1 \\
\hline Fearful- Fearless & Very fearful & 52.2 \\
\hline Angry- Peaceful & Very angry & 53.1 \\
\hline Insulted- Flattered & Very insulted & 59.4 \\
\hline $\begin{array}{c}\text { Concerned about looks- } \\
\text { Unconcerned about looks }\end{array}$ & $\begin{array}{c}\text { Very concerned } \\
\text { about looks }\end{array}$ & \\
\hline
\end{tabular}

Table 3 shows the most frequently chosen response (feelings regarding the harassment experience) and the \% of participants' responses to the Reaction to Harassment Scale.

Table 4 shows the correlation between experience of street harassment and perceived fear of victimization

\begin{tabular}{|c|c|}
\hline & Fear of victimization \\
\hline Street harassment total Pearson Correlation & $.216^{* *}$ \\
\hline Sig. (2-tailed) & 0.002 \\
\hline $\mathrm{N}$ & 250 \\
\hline$* *$. Correlation is significant at the .01 level (2-tailed). & \\
\hline
\end{tabular}

Table 4 illustrates a significant positive correlation between street harassment and fear of victimization. 
Table 5 depicts correlation between the reaction to harassment (sub scale) and fear of victimization

\begin{tabular}{|c|c|c|}
\hline & & Fear of Victimization \\
\hline \multirow[t]{3}{*}{ Reaction to Harassment (subscale) } & Pearson Correlation & $0.404 * *$ \\
\hline & Sig. (2-tailed) & 0.000 \\
\hline & $\mathrm{N}$ & 250 \\
\hline \multicolumn{2}{|c|}{ **.Correlation is significant at the .01 level } & \\
\hline
\end{tabular}

Table 5 illustrates a significant, positive correlation between reaction to harassment and perceived fear of victimization

\section{Discussion}

The topic of street harassment is not one which has received much attention and yet this experience has been a common occurrence for many people, especially women in different societies and cultures. The results of this study have been found to be in agreement with the hypothesis. A positive correlation between experiencing street harassment and fear of victimization was found and a significant correlation of .216 (Refer: table 4) at alpha value 0.01 was attained. A research conducted in USA also provided similar results indicating that stranger harassment makes women more fearful of victimization because of a decreased sense of power ${ }^{13}$. Therefore, it was concluded that women who receive a lot of unwanted sexual attention and harassment learn to be more perceptive of danger of sexual violence and are generally more fearful. Another reason provided for the relationship between street harassment and fear of victimization could be that women who have prior experience with any sort of victimization are most likely to be more fearful of future incidences of crime. Evidence for this can be provided in a study where a sample of 3109 residents of a town in Carolina, USA were analyzed, and it was found that with a rise in degree of victimization experiences, the fear of crime also increased ${ }^{14}$. Applying this scenario in this society, within the past 7 to 8 years, Karachi has become a violent and fear-ridden city. According to the statistics mentioned in an article on Express Tribune ${ }^{15}$; since 2005 , killing by gunshot per year have increased at a rate of 50\% annually for the next seven years along with a rapid increase in other crimes such as mobile, car snatching and kidnapping. In light of the

13. Nita M McKinley and Janet S Hyde, "The objectified body consciousness scale: Development and validation". Psychology of Women Quarterly, (July 2006):20, 181-215.

${ }^{14}$ Lynn N Smith and Gary D Hill, "Victimization and fear of crime". Journal of Criminal Justice and Behavior, 18(4), 1991, 217-239.

${ }^{15}$ Saad Amanullah, "Living in Fear: For Businesses and Citizens of Karachi, Crime Conquers All”. Express Tribune. http://tribune.com.pk/story/535525/living-in-fear-for-businesses-and-citizens-of-karachi-crimeconquers-all/ 
international researches done on the effects of prior victimization, it should not be surprising if the experience of fear of crime has become a norm for the citizens of Karachi.

Even though the results concluded a significant, positive correlation between experiencing street harassment and fear of victimization were recorded, the correlation is relatively weak suggesting there might be other factors influencing the variables. Pakistani society along with many other South Asian countries, is by nature a patriarchal society ${ }^{16}$ and even though this patriarchy gives rise to numerous negative consequences, one advantage of such society is that even if a strange woman is being troubled or harassed by strangers in a public place, other men witnessing the act come to the aid of the woman and ensure her well-being. The prevalence of such incidences might have caused the relationship of street harassment and fear of being victimized to be not as strong as in the Western societies.

Furthermore, research on demographic factors leading to higher fear of victimization indicates that women that practice constrained or precautionary behavior are less likely to be influenced by it. ${ }^{17}$ The most common medium of engaging in safety behavior in this society is to be accompanied by a man, and those who do, are generally less susceptible to both the experiences of street harassment as well as the fear of crime ${ }^{18}$.

Through this research, we were also able to identify which of the harassing behaviors occurred most frequently. According to the results, (refer table 2) staring was the most common harassing behavior and a high average was found for unwanted touching and being followed. These results can be further validated by a blog published in the EDawn newspaper ${ }^{19}$, where the blogger highlighted the extent of verbal and physical harassment faced by women while commuting on a public bus in Karachi.

Additionally, the attitudes towards street harassment were also investigated in this study and as depicted in Table 3 most of the women reported feeling extremely negative emotions and attitudes towards street harassment. $67 \%$ of the participants reported feeling very worried after experiencing such behaviors and an internet based survey conducted in USA on a sample of 2000 people suggested that the level of worry caused by street harassment experiences could increase to an extent where the victims would engage in avoidance behaviors eventually leading up to changing their neighborhoods or switching jobs ${ }^{20}$.

\footnotetext{
${ }^{16}$ Manzoor Ali Isran and Samina Isran "Patriarchy and women in Pakistan: A critical analysis". Interdisciplinary Journal of Comtemporary research in business. (October 2012).

${ }^{17}$ Margaret T Gordon et al "Crime, women, and the quality of urban life" Signs, 1980. http://www.jstor.org/stable/3173812

${ }^{18}$ Esther Madriz "Nothing bad happens to good girls: Fear of crime in women's lives" (October 2015)http://www.d.umn.edu/cla/faculty/jhamlin/3925/Readings/imagesFear.pdf

${ }^{19}$ Faiza Mirza "She asked for it". Express Tribune. (February 2014). http://www.dawn.com/news/783565/sheasked-for-it-

${ }^{20}$ Holly Kearl, "Stop street harassment: Making public places safe and welcoming for women". http://hollykearl.com/events/UCSBtalk10.13.10.pdf
} 
Approximately, 52\% of the participants in this study also felt very fearful after their experience with street harassment (refer table 3) and similar findings were found by a research done in Delhi ${ }^{21}$. In that study, 20 women who had prior experience with street harassment were interviewed about their feelings and coping mechanisms regarding it and the participants reported that as their experience with street harassment became recurrent, their fear and anger towards it also heightened. Moreover, recent researches have also suggested that experiencing such incidences of street harassment causes women to become increasingly aware of their sexual vulnerability, therefore also escalating their fear of sexual assault during such encounters by multiple times ${ }^{22}$.

Additionally, more than $59 \%$ of the participants reported feeling very insulted by the harassing experiences and therefore it can be concluded that such stranger harassment experiences might have lead to a feeling of indignation and disrespect amongst the victims.

Moreover, the results also suggested that $44.4 \%$ of the participants felt very conscious about their looks (refer table 3) during such experiences. Previous studies have found that street harassment has been positively related to women self-objectification. Selfobjectification further causes women to be occupied by anxiety, depression and eating disorders $^{23}$.

In addition to that, the results of this research also provided a significant positive correlation between reaction to harassment and perceived fear of victimization ( refer table 5), which means that the more negative the reaction to harassment is, the greater is the fear of victimization or vice versa. A major reason for this could be that the fear of street harassment escalating into sexual assault or rape is quite high ${ }^{24}$. The fear of what the harasser might do next, especially in a society which lacks the implementation of law; victims might react quite negatively to the experience as well as have a high fear of crime in general.

It was observed during this research that strong cultural stigmas are associated with sharing one's harassment experiences as a result of which mostly females in the younger age group responded to this research and consented to sharing their harassment experiences (refer table $6 a$ ). Additionally, over $75 \%$ of the respondents were students (refer table 6b) and further research investigating whether this is the target age group for street harassment or whether this is the age group willing to openly discuss such issues should be conducted.

\footnotetext{
${ }^{21}$ Tracy Lynn Lord, 'The Relationship of Gender-Based Public Harassment to Body Image, Self-Esteem, and Avoidance Behavior"(2009).

${ }^{22}$ MacMillan, Annette Nierobisz and Sandy Welsh, "Experiencing the streets: Harassment and perceptions of safety among women" Journal of Research in Crime and Delinquency,37, 306-322. (August 2000)

${ }^{23}$ Barbara L Frederickson and Tomi-Ann Roberts "Objectification theory: Towards women's lived experiences and mental health risks" Psychology of Women Quarterly (July 2006).

${ }^{24}$ Holly Kearl, "Stop street harassment: Making public places safe and welcoming for women". http://hollykearl.com/events/UCSBtalk10.13.10.pdf (2010).
} 


\section{Conclusion and Limitation}

Street harassment was established as having a positive relationship with fear of crime and severe, negative attitudes towards such experiences were found in the participants. Moreover, staring, comments on appearance, non-verbal gestures and being followed by a stranger were also highlighted as the most prevalent forms of harassing behaviors.

Limitation of this research was the lack of participants in different demographic variables and further researches exploring the stigma regarding street harassment and coping mechanisms should be conducted.

\section{Bibliography}

AAUW Educational Foundation, "Hostile hallways: The AAUW survey on sexual harassment in America's schools" (Washington, DC, 1993).

Anila, "Perception of sexual harassment among a group of male and female medical college students", Pakistan Journal of Psychological Research, (1990),55-67.

Anila, "Sexual harassment: Myths versus women's reality". Paper presented at the $8^{\text {th }}$ International Conference of Pakistan Psychological Association, Islamabad, (1991).

Barbara L Frederickson and Tomi-Ann Roberts "Objectification theory: Towards women's lived experiences and mental health risks" Psychology of Women Quarterly (July 2006).

Bonnie S Fisher and John J Sloan, "Unraveling the fear of victimization among college women: Is the "shadow of sexual assault hypothesis" supported?" Journal of Justice Quarterly, (August 2006): 633-659.

Esther Madriz "Nothing bad happens to good girls: Fear of crime in women's lives" (October 2015)http://www.d.umn.edu/cla/faculty/jhamlin/3925/Readings/imagesFear.pdf

Faiza Mirza "She asked for it". Express Tribune. (February 2014). http://www.dawn.com/news/783565/she-asked-for-it-

Ferraro, K. F., \& LaGrange, R.L. Are older people most afraid of crime? Reconsidering age differences of victimization. Journals of Gerontology, (1992) 47, S233-S244.

Holly Kearl, "Stop street harassment: Making public places safe and welcoming for women". http://hollykearl.com/events/UCSBtalk10.13.10.pdf

Holly Kearl, "Stop street harassment: Making public places safe and welcoming for women". http://hollykearl.com/events/UCSBtalk10.13.10.pdf (2010).

Lord, T. L. "The Relationship of Gender-Based Public Harassment to Body Image,SelfEsteem, and Avoidance Behavior". Indiana University of Pennsylvania, (2009). 
Louise F. Fitzgerald, Michele Gelfand and Fritz Drasgow, "Measuring sexual harassment: Theoretical and psychometric advances" Journal of Social and Applied Social Psychology, 1995, 425-445.

Lynn N Smith and Gary D Hill, "Victimization and fear of crime". Journal of Criminal Justice and Behavior, 18(4), 1991, 217-239.

MacMillan, Annette Nierobisz and Sandy Welsh, "Experiencing the streets: Harassment and perceptions of safety among women" Journal of Research in Crime and Delinquency,37, 306-322. (August 2000)

Manzoor Ali Isran and Samina Isran "Patriarchy and women in Pakistan: A critical analysis". Interdisciplinary Journal of Comtemporary research in business. (October 2012).

Margaret T Gordon et al "Crime, women, and the quality of urban life" Signs, 1980. http://www.jstor.org/stable/3173812

Nita M McKinley and Janet S Hyde, "The objectified body consciousness scale: Development and validation". Psychology of Women Quarterly, (July 2006):20, 181215.

Paula M Meek, "Establishing an informal grievances procedure for cases of sexual harassment of students."Journal of NAWDAC, 1983,46 (2)30-33.

Rhonda Lenton, Michael D Smith et al, "Sexual harassment in public places: Experiences of Canadian women", Canadian Review of Sociology and Anthropology, 1999, 517-540.

Ross MacMillan, Annette Nierobisz and Sandy Welsh, "Experiencing the streets: Harassment and perceptions of safety among women" Journal of Research in Crime and Delinquency,37, 306-322. (August 2000).

Saad Amanullah, "Living in Fear: For Businesses and Citizens of Karachi, Crime Conquers All”. Express Tribune. http://tribune.com.pk/story/535525/living-in-fear-forbusinesses-and-citizens-of-karachi-crime-conquers-all/

Shannan M Catalano, “Criminal victimization 2004”. Bureau of Justice Statistics. National Crime Victimization Survey (September 2005).

Susan E Hickman and Charlene L Muehlenhard, "College women's fears and precautionary behaviors relating to acquaintance rape and stranger rape" Psychology of Women Quarterly (July 2006): 527-547.

Tracy Lynn Lord, 'The Relationship of Gender-Based Public Harassment to Body Image, Self-Esteem, and Avoidance Behavior”(2009). 